\title{
Bioanalysis
}

\section{Serum apolipoprotein A-1 quantification by LC-MS with a SILAC internal standard reveals reduced levels in smokers}

\begin{abstract}
Background: Absolute quantification of protein biomarkers such as serum apolipoprotein A1 by both immunoassays and LC-MS can provide misleading results. Results: Recombinant ApoA-1 internal standard was prepared using stable isotope labeling by amino acids in cell culture with $\left[{ }^{13} \mathrm{C}_{6}^{15} \mathrm{~N}_{2}\right]$-lysine and $\left[{ }^{13} \mathrm{C}_{9}^{15} \mathrm{~N}_{1}\right]$-tyrosine in human cells. A stable isotope dilution LC-MS method for serum ApoA-1 was validated and levels analyzed for 50 nonsmokers and 50 smokers. Conclusion: The concentration of ApoA-1 in nonsmokers was $169.4 \mathrm{mg} / \mathrm{dl}$ with an $18.4 \%$ reduction to $138.2 \mathrm{mg} / \mathrm{dl}$ in smokers. The validated assay will have clinical utility for assessing effects of smoking cessation and therapeutic or dietary interventions in high-risk populations.
\end{abstract}

Apolipoproteins are high abundance serum proteins situated on the surface of lipoprotein particles that transport highly hydrophobic lipids. Current evidence suggests apolipoprotein $\mathrm{A} 1$ (ApoA-1) is a potential diagnostic biomarker for coronary heart disease risk [1,2]. Furthermore, the risk of coronary heart disease is strongly associated with increased adiposity, which can be further increased by smoking behavior [3,4]. Advances in MS, proteomics and protein bioanalytical approaches led to a rapid evolution and expansion in the area of MS-based biomarker discovery and development $[5,6]$. Once a biomarker has been identified as a clinically relevant target, quantitative assays must be developed for diagnosis and prognosis of disease. Such quantitative assays should be sensitive, specific, robust, scalable as well as objective with high intra- and inter-laboratory reproducibility. Quantitative immunoassays such as ELISAs are widely used for quantifying protein biomarkers due to their high-throughput capabilities and high sensitivity [7]. Nevertheless, immunoassays based on epitope recognition can suffer from technical problems including weak antibody affinity, high cross-reactivity and lack of concordance among platforms [8]. There is also a potential for cross-reactivity of the antibody with other high abundance proteins that are present in serum [9]. This can be avoided by specific protein purification prior to analysis. Unfortunately, selective losses can occur during the purification process leading to additional uncertainty in the analytical result [10]. Stable isotope dilution liquid chromatography-selected reaction monitoring (LC-SRM)/MS or LC-multiple reaction monitoring (MRM)/MS can provide a solution to these potential problems [11-15]. However, the cost and requirement for skilled researchers limits the utility of LC-MS-based procedures so that they are normally only used as confirmatory methods or when analyses of complex protein mixtures are required [16].

Typically, protein quantification by LC-MS is performed using isotopically labeled tryptic peptides specific to the protein of interest as internal standards, a strategy known as Absolute Quantification (AQUA) [17,18]. Quantification of ApoA-1 by LC-SRM/MS or LC-MRM/MS employing AQUA peptides has been reported for purified ApoA-1 [19,20], serum and plasma ApoA-1 [21-25], and isolated HDL particles [26,27]. In a recent report [28], LC-MRM/MS using AQUA peptides was used for quantification and confirmation of ApoA-1 as a candidate biomarker. The
Qingqing Wang ${ }^{1,2,3}$, Suhong Zhang ${ }^{1,2}$, Lili Guo ${ }^{1,2}$, Christine M Busch ${ }^{1,2}$, Wenying Jian, Naidong Weng ${ }^{4}$, Nathaniel W Snyder $1,2,5$, Kannan Rangiah ${ }^{1,2,6}$, Clementina Mesaros ${ }^{1,2} \&$ Ian A Blair ${ }^{*, 1,2}$ ${ }^{1}$ Center of Excellence in Environmental Toxicology \& Penn SRP Center, Perelman School of Medicine, University of Pennsylvania Philadelphia, PA 19104, USA

${ }^{2}$ Department of Systems Pharmacology \& Translational Therapeutics, Perelman School of Medicine, University of Pennsylvania Philadelphia, PA 19104, USA

${ }^{3}$ Department of Pharmacology \& Toxicology, Beijing Institute of Radiation Medicine, Beijing, 100850, China

4Janssen Research \& Development, Johnson \& Johnson, 1400 McKean Road, Spring House, PA 19477, USA

${ }^{5}$ AJ Drexel Autism Institute, Drexel University, Philadelphia, PA 19104, USA ${ }^{6}$ Metabolomics Facility, Centre for Cellular \& Molecular Platforms, GKVK, Bellary Road, Bangalore 560065, India *Author for correspondence:

Tel.: +1 2155739880

Fax: +1 2155739889

ianblair@mail.med.upenn.edu 


\section{Key terms}

ApoA-1: Apolipoprotein A1 (ApoA-1) is the major component of high-density lipoprotein. Current evidence suggests ApoA-1 is a potential diagnostic biomarker for cardiovascular disease.

LC-MRM/MS: A typical analytical technology for quantification of proteins. Two stages of mass filtering are employed on a triple quadrupole mass spectrometer in the LC-MRM/MS mode. One precursor ion is selected in Q1 (usually doubly charged protonated molecule), and different sequence-specific product ions are analyzed in Q3.

AQUA peptide(s): Stable isotope labeling peptide(s), which are produced by peptide synthesis with labeled amino acids for use as internal standard(s) in protein or peptide Quantification (AQUA). Typically, AQUA peptides specific to the protein of interest are added in the sample after protein separation and tryptic digestion step.

SILAC: Stable isotope labeling by amino acids in cell culture (SILAC) has emerged with LC-MS as an accurate, robust and efficient technology for comparative analysis of different cell populations. Usually, two cell populations are cultured in the presence of heavy or light amino acids, one of them is subjected to a treatment and then combined and processed together.

SILAC-labeled internal standard(s): Stable isotope labeled protein(s) (produced by a SILAC approach) are used as an internal standard for protein quantification. They added to samples in order to correct for losses during sample clean up, peptide decomposition during protein hydrolysis and losses through binding to active surfaces. The use of SILAC protein internal standards minimizes differences in sample processing and proteolytic digestion between the standard and its endogenous counterpart. They provide the most accurate and precise method for absolute protein quantification when combined with standard curves employing known amounts of the corresponding standard unlabeled endogenous protein.

differential expression of ApoA-1 was established in 24 hepatocellular carcinoma (HCC) and 26 hepatitis C-infected (HCV) patients. The three MRM/MS transitions and western blotting showed similar relative expression levels. However, absolute concentrations of ApoA-1 calculated from the three tryptic peptides were up to three-fold different for an individual patient. Another study evaluated the trypsin digestion efficiency by monitoring various tryptic peptides, derived from ApoA-1 and ApoB [12]. Although AQUA peptides were added before the tryptic digestion, formation and decomposition of individual monitored peptides was highly variable. This suggested that the selection of rapidly formed peptides with no or minor missed cleavages and the use of short trypsin incubation times were likely to reduce the improved accuracy. Therefore, the AQUA approach is recommended for use with proteins that readily undergo digestion to peptides that are stable to further hydrolysis [11].
Ideally, a full length isotope-labeled protein as an internal standard should be added at the start of the analytical process. Protein standard absolute quantification (PSAQ) utilizes a cell-free biosynthesis system [29], which expresses the target protein $(s)$ with recombinant his-tag in combination with $\mathrm{Ni}$-column purification or by immunoprecipitation. Unfortunately, different rates of degradation between the endogenous and PSAQ protein caused by serum proteases as well as different recoveries during clean-up stages have been observed [29-31]. Two new strategies for stable isotope labeling by amino acids in cell culture (SILAC) termed 'stable isotope labeled proteome (SILAP) standard' and 'absolute SILAC' were introduced in 2005 and 2008 [32,33], respectively to circumvent this problem. SILAC-labeled recombinant proteomes produced in vitro or in vivo are used as internal standards, which are directly mixed into lysates of cells or tissues [33-36], or appropriate biofluids such as cervicovaginal fluid and serum [37-39]. Two related SILACbased approached known as spike-in SILAC [40-43] and super-SILAC [44-46] have been reported in which SILAC cells or whole animals are used to produce labeled protein internal standards. In contrast to the classical SILAC method [47], these approaches can be applied to a large variety of samples [40]. The use of SILAC-labeled internal standards minimizes differences in sample processing and proteolytic digestion between the standard and its endogenous counterpart. Therefore, SILAC-based strategies can provide the most accurate and precise methods for absolute protein quantification [48].

We report a fully validated method for the quantification of ApoA-1 in human serum using a spike-in SILAC approach. A number of methods have been reported previously that primarily used labeled ApoA-1 tryptic peptides as internal standard (Supplementary Table 1). The SILAC-labeled ApoA-1 internal standard used in the present study was labeled with $\left[{ }^{13} \mathrm{C}_{6}^{15} \mathrm{~N}_{2}\right]$-lysine and $\left[{ }^{13} \mathrm{C}_{9}{ }^{15} \mathrm{~N}_{1}\right]$-tyrosine and expressed in the human kidney HEK293 cell line. The recombinant labeled ApoA-1 was expressed without a His tag (HHHH$\mathrm{HHH}$ ) or V-epitope tag (GKPIPNPLLGLDST) commonly used for recombinant protein purification and identification. SILAC-labeled ApoA-1 was spiked into serum samples at the beginning of the whole sample preparation procedure - before electrophoresis separation and tryptic digestion. Full validation was performed by employing nine tryptic peptides generated from native ApoA-1 and SILAC-labeled ApoA-1 in order to maximize coverage of the endogenous ApoA-1 protein. Our approach was systematically compared with traditional AQUA and ApoA-1 levels in 50 smokers and 50 nonsmokers were then determined. 
Table 1. Demographics for study cohort of 50 nonsmokers and 50 smokers.

\begin{tabular}{|c|c|c|c|c|c|c|c|c|c|c|}
\hline \multicolumn{2}{|c|}{ Tobacco history } & \multicolumn{2}{|c|}{ Gender } & \multicolumn{3}{|c|}{$\mathrm{Age}^{\dagger}$} & \multicolumn{4}{|c|}{ Race } \\
\hline & Total & Male & Female & $25-40$ & $41-60$ & $61-84$ & Caucasian & $\begin{array}{l}\text { African- } \\
\text { American }\end{array}$ & Asian & Other \\
\hline Current & 50 & 26 & 24 & 8 & 13 & 28 & 90 & 7 & 2 & 1 \\
\hline Never & 50 & 20 & 30 & 5 & 28 & 16 & & & & \\
\hline
\end{tabular}

The serum concentrations were then compared with those obtained from a commercial ELISA kit.

\section{Materials \& methods \\ Clinical samples}

Serum samples were from 100 subjects (50 nonsmokers, 50 smokers) enrolled in an ongoing study of tobacco biomarkers at the University of Pennsylvania School of Medicine. The demographic information is summarized in Table 1 and complete patient information is provided in Supplementary Table 2). All samples were immediately aliquoted and frozen at $-80^{\circ} \mathrm{C}$ until analysis. The study was approved by the Institutional Review Board at the University of Pennsylvania (Protocol \# 800924).

\section{Reagents \& chemicals}

All reagents and solvents were LC-MS grade quality unless otherwise noted. The gene for human ApoA-1 in the Gateway entry vector pFN21AE0099, FuGENE ${ }^{\circledR} 6$ transfection reagent, protease inhibitors, and mammalian cell lysing buffer purchased from Promega (Madison, WI, USA). Human ApoA-1 isolated from human HDL was from ProSpec (East Brunswick, NJ, USA). Mouse serum was from Sigma-Aldrich (St. Louis, MO, USA). SILAC amino acids including $\left[{ }^{13} \mathrm{C}_{6}{ }^{15} \mathrm{~N}_{2}\right]$-lysine and $\left[{ }^{13} \mathrm{C}_{9}{ }^{15} \mathrm{~N}_{1}\right]$-tyrosine were from Cambridge Isotope Laboratories (Andover, MA, USA). DL-dithiothreitol (DTT), iodoacetamide (IAA) and dialyzed fetal bovine serum was from Sigma-Aldrich. 2-mecaptoethanol (BME) was from BioRad (Hercules, CA, USA). Ammonium bicarbonate (ABC) and formic acid were purchased from Fisher Scientific (Pittsburgh, PA, USA). Colloidal Coomassie and sequencing-grade modified trypsin from Promega. LC grade water and acetonitrile were from Burdick and Jackson (Muskegon, MI, USA). Custom-made AQUA peptides corresponding to endogenous peptides of trypsin-digested ApoA-1 were purchased from Thermo Scientific (Isotopic enrichment $>99 \%$, HeavyPeptide AQUA custom synthesis service (Rockford, IL, USA).

\section{Expression of SILAC-labeled ApoA-1}

The sequence of ApoA-1 was amplified by PCR reaction from ApoA-1 cDNA plasmid purchased from Promega (Supplementary Figure 1). The primer pair for PCR application contains BamHI and SalI restriction enzyme sites in their tails. The sequences of primers were: 5'-CGCGGATCCGCCACCATGAAAGCTGCGGTGCTGA-3' and 5'-CGCGTCGACTCACTGGGTGTTGAGCTTCTTAG-3'. PCR was performed as follows: $94^{\circ} \mathrm{C}$ for $4 \mathrm{~min}$, followed by 30 cycles of denaturation $\left(94^{\circ} \mathrm{C} ; 45 \mathrm{~s}\right)$, annealing $\left(55^{\circ} \mathrm{C}\right.$; $45 \mathrm{~s})$ and extension $\left(72^{\circ} \mathrm{C} ; 60 \mathrm{~s}\right)$, in a final volume of $50 \mu$ containing DNA polymerase (New England Biolabs, Ipswich, MA, USA), $1 \times$ ThermoPol Reaction Buffer (New England Biolabs), 0.1 M of each primer, $0.2 \mathrm{mM}$ of each deoxyribonucleotide and $1 \mathrm{ng}$ template DNA. PCR products and pRK5 vectors were digested by BamHI and SalI restriction enzymes (New England, Biolabs) for $5 \mathrm{~h}$ according to the manufacturer's instruction. The digested fragments were purified by gel extraction kit (Qiagen, Gmbh, D, Hiden) and ligated by T7 DNA ligase (New England Biolabs) according to manufacturers' instruction. The ligation product was transformed into DH5aphla E. coli competent cells by calcium chloride transformation. Transformed E. coli was plated on LB agar plate containing ampicillin. Three bacterial colonies were picked and checked for ApoA-1 insertion by BamHI and SalI digestion of DNA prepared from mini prep. pRK5 plasmid containing ApoA-1 sequence was confirmed by DNA sequencing. For the expression of SILAC-labeled ApoA-1 protein, the human kidney HEK293 cell line was used. ApoA-1 pRK5 plasmid was transfected into HEK293 cells using FuGENE 6 transfection reagent (Promega) following manufacturer's instruction. Transfected cells were cultured in SILAC medium containing $\left[{ }^{13} \mathrm{C}_{6}^{15} \mathrm{~N}_{2}\right]$-lysine and $\left[{ }^{13} \mathrm{C}_{9}{ }^{15} \mathrm{~N}_{1}\right]$-tyrosine for $24 \mathrm{~h}$ before harvesting. After washing with DPBS (Dulbecco's Phosphate-Buffered Saline), cells were scraped into PBS and centrifuged at $4000 \mathrm{rpm}$ for $30 \mathrm{~min}$. The cell pellets were lysed in mammalian cell lysis buffer (Promega) containing protease inhibitor cocktail (Promega). The lysate was centrifuged at $17,000 \mathrm{rpm}$ for $1 \mathrm{~h}$ at $4^{\circ} \mathrm{C}$. The supernatant was aliquoted and stored at $-80^{\circ} \mathrm{C}$ until analyzed.

\section{Sample preparation for LC-MRM/MS}

All serum samples were thawed at room temperature, and $10 \mu \mathrm{l}$ of each sample was diluted five times with 
DPBS. To each $5 \mu \mathrm{l}$ of this dilution $(=1 \mu \mathrm{l}$ serum $)$, $5 \mu \mathrm{l}$ of SILAC-ApoA-1, $5 \mu \mathrm{l}$ of DPBS, $3 \mu \mathrm{l}$ of BME and $7 \mu \mathrm{l}$ of NuPage LDS sample loading buffer ( $4 \times$, Promega) were added. This mixture was denatured at $95^{\circ} \mathrm{C}$ for $10 \mathrm{~min}$ before loading on SDS-PAGE gel. The serum proteins were separated by SDS-PAGE using NuPage Novex 10\% Bis-Tris gels and Nupage MOPS running buffer (Promega) according to the manufacturer's instruction. The gels were stained with colloidal Coomassie (Promega). Gel slices were cut into $1 \mathrm{~mm}^{3}$ cubes, washed twice with destain buffer containing $50 \mathrm{mM} \mathrm{ABC}$ and $50 \%$ acetonitrile, then incubated with $10 \mathrm{mM}$ DTT in $25 \mathrm{mM} \mathrm{ABC}$ for $1 \mathrm{~h}$ at $60^{\circ} \mathrm{C}$ for protein reduction. The resulting free thiol groups were subsequently alkylated by incubating the samples with $55 \mathrm{mM}$ IAA in $25 \mathrm{mM} \mathrm{ABC}$ for $1 \mathrm{~h}$ at room temperature in the dark. The gel pieces were washed twice with $50 \mathrm{mM} \mathrm{ABC}$, dehydrated with acetonitrile and dried in a vacuum concentrator (Jouan RC10.22 by Thermo Fisher Scientific). The gel pieces were rehydrated with $150 \mu \mathrm{l}$ of trypsin in $20 \mathrm{mM} \mathrm{ABC}$ for $1 \mathrm{~h}$ on ice followed by digestion at $37^{\circ} \mathrm{C}$ overnight. On the second day, the supernatants were transferred to clean tubes and the gel pieces were extracted by $50 \%$ acetonitrile with $3 \%$ formic acid by sonicating $20 \mathrm{~min}$. The extracts were combined with supernatants, and dried in a vacuum concentrator. Desalting and concentration were carried out on Macrospin column (The Nest Group, Inc., Southborough, MA, USA) according to manufacturer's instruction. The eluted peptides were dried and re-suspended with $50 \mu \mathrm{l}$ of mobile phase A. AQUA approach followed the same protocol, except the AQUA peptides (30 pmol/sample) were added after tryptic digestion.

\section{Method validation by SILAC-labeled ApoA-1}

Mouse serum was used as surrogate matrix for preparation of calibration standards and quality controls (QCs). Mouse serum was five-fold diluted with DPBS to mimic the matrix effect in human serum samples. Calibration standards were prepared by spiking appropriate amounts of the ApoA-1 standard to five-fold diluted mouse serum to make the final concentrations of 15.6, $31.3,62.5,125,250.0$ and $500.0 \mathrm{mg} / \mathrm{dl}$. The preparation procedures for QC samples at concentrations of $22.5,200.0$ and $400.0 \mathrm{mg} / \mathrm{dl}$ were the same as that of the calibration standards. Five microliters of SILAClabeled ApoA-1 were added to each calibration standard and QC sample before loading samples on the SDSPAGE gel. Assay validation was conducted according to the principles described in US FDA criteria guidelines for bioanalytical methods [49]. Linearity of standard curves was evaluated from 15.6 to $500.0 \mathrm{mg} / \mathrm{dl}$. LLOQ was defined as the lowest calibration level, which could be fitted to the calibration curve with a residual of less than $10 \%$, and peak area ratio deviating less than $25 \%$. The accuracy and precision were determined on five replicates of low quality control (LQC), middle quality control (MQC) and high quality control (HQC) samples running on the same day (intraday) and on five different days (interday).

\section{LC-MRM/MS analysis}

LC-MRM/MS was performed on a TSQ Vantage (Thermo Fisher Scientific, San Jose, CA, USA) equipped with a CaptiveSpray ${ }^{\mathrm{TM}}$ ion source (Michrom Bioresources, Inc., Auburn, CA, USA). The mass spectrometer was interfaced with a Waters nanoAcquity UPLC system (Waters Corporation, Milford, MA, USA) equipped with an autosampler and sample thermo-controller (set at $4^{\circ} \mathrm{C}$ ). Both the UPLC and mass spectrometer were controlled by Xcalibur software (Thermo Scientific). The syringe was washed with methanol/acetonitrile $(50: 50 ; \mathrm{v} / \mathrm{v})$ containing $0.01 \%$ formic acid after every injection. Separations were performed using a Waters BEH130 C18 column $(150 \mu \mathrm{m} \times 100 \mathrm{~mm} ; 1.7 \mu \mathrm{m} ; 130 \AA$ ) (Waters Corporation) at $30^{\circ} \mathrm{C}$ using a partial loop injection. Samples were eluted with a linear gradient at a flow rate of $2 \mu \mathrm{l} / \mathrm{min}$. Solvent A was water/acetonitrile (99.5:0.5; $\mathrm{v} / \mathrm{v})$ containing $0.1 \%$ formic acid, and solvent $B$ was acetonitrile/water $(98: 2, \mathrm{v} / \mathrm{v})$ containing $0.1 \%$ formic acid. The gradient started with $5 \% \mathrm{~B}$, held for $5 \mathrm{~min}$, then linearly increased to $60 \% \mathrm{~B}$ over $35 \mathrm{~min}$. After washing with $95 \%$ B for $5 \mathrm{~min}$, the column was re-equilibrated with $5 \% \mathrm{~B}$ for $10 \mathrm{~min}$ prior to the next injection. The MS operating conditions were as follows: spray voltage, $1800 \mathrm{~V}$; ion transfer capillary temperature, $270^{\circ} \mathrm{C}$; collision gas, argon at 1.5 mTorr; ion polarity, positive; scan type, selected reaction monitoring (SRM); chrome filter peak width, $15 \mathrm{~s}$; S-lens, $127 \mathrm{v}$; cycle time, 1.5 s; Q1 peak width (FWHM), $0.7 \mathrm{u}$; Q3 peak width, $0.7 \mathrm{u}$; dissociation voltage (DCV), $10 \mathrm{~V}$. MRM transitions were selected based on the LC-MS/MS spectra on a TSQ Vantage. The peak area ratio of each MRM/MS transition for each unlabeled/light (L) peptide to labeled/heavy $(\mathrm{H})$ peptide was calculated by the Skyline software package (MacCoss Lab, Department of Genome Sciences, UW) and used for absolute quantification (Supplementary Table 3). The peptide ratios were calculated by the total $\mathrm{L} / \mathrm{H}$ ratios of the three MRM/MS transitions. The ApoA-1 ratios were calculated by the average of nine selected peptides. Serum concentrations of tryptic peptides and ApoA-1 were obtained by interpolation from a standard curve prepared in mouse serum because murine ApoA-1 has no tryptic peptides that are identical with the nine that were chosen for analysis of human serum ApoA-1 (Figure 1A). 
Determination of ApoA-1 by ELISA

An ApoA-1 Human ELISA Kit (Abcam, ab108804, Cambridge, MA, USA) was used to analyze serum samples, and performed according to the kit protocol insert. Serum samples were diluted 100 -fold with the kit dilution buffer. One set of calibration curve and two sets of QCs were placed on each plate. Mouse serum was used as the blank. The assay range was from 1.3 to $20 \mu \mathrm{g} / \mathrm{ml}(0.13-2.0 \mathrm{mg} / \mathrm{dl})$ in human serum.

\section{Data processing}

Data analysis was performed in Skyline (MacCoss Laboratory, University of Washington, Seattle, WA, USA).
Statistical analysis was performed using GraphPad Prism (v 5.01, GraphPad Software Inc., La Jolla, CA, USA). Linear regressions were used to calculate the Pearson correlation coefficients $\left(\mathrm{R}^{2}\right)$ for peptide correlations. Deming regressions [50] and the Bland-Altman method [51,52] were applied to assess the agreement between the ELISA and LC-MRM/MS assay.

\section{Results \& discussion}

Selection of quantitative peptides \& MRM transitions

To develop a robust and accurate quantification method for determination of ApoA-1 in human serum or plasma,

(A)

10

(1) 20

30

(2) 40

50

Human \& DEPPQSPWDR VKDLATVYVD VLKDSGRDYV SQFEGSALGK QLNLKLLDNW Murine \& DEPQSQWDK VKDFANVYVD AVKDSGRDYV SQFESSSLGQ QLNLNLLENW
(3) 60
70
80
90
100

DSVTSTFSKL REQLGPVTQE FWDNLEKETE GLRQEMSKDL EEVKAKVQPY DTLGSTVSQL QERLGPLTRD FWDNLEKETD WVRQEMNKDL EEVKQKVQPY_
(4) 110
(5) 120
130
140
150

LDDFQKKWQE EMELYRQKVE PLRAELQEGA RQKLHELQEK LSPLGEEMRD LDEFQKKWKE DVELYRQKVA PLGAELQESA RQKLQELQGR LSPVAEEFRD

$\begin{array}{lllllll}160 & (6) & 170 & 180 & 190 & \text { (7) } & 200\end{array}$

RARAHVDALR THLAPYSDEL RQRLAARLEA LKENGGARLA EYHAK ATEHL RMRTHVDSLR TQLAPHSEQM RESLAQRLAE LKSNPTLNEY HTRAK THLKT
(8) 210
220
230
(9) 240
STLSEKAKPA LEDLRQGLLP VLESFKVSFL SALEEYTKKL NTQ
LGEKARPALE DLRHSLMPML ETLKTQVQSV IDKASETLTA Q

(B)

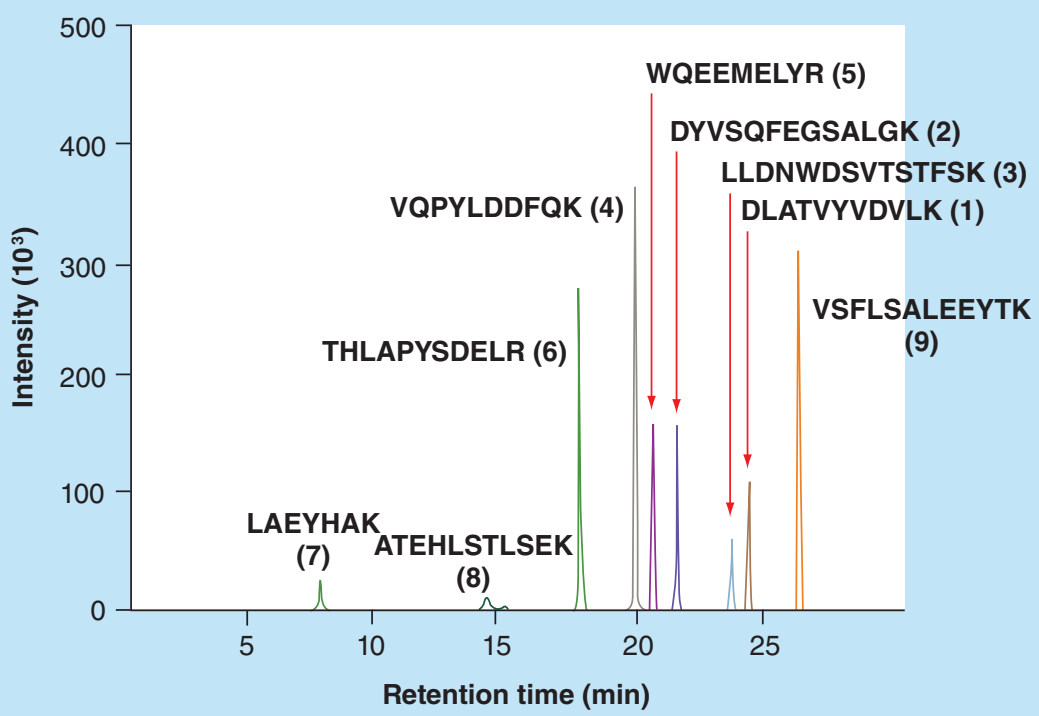

Figure 1. (A) Comparison of human (upper line) and mouse (lower line) ApoA-1 sequence, and tryptic peptides used for quantification (underlined bold). (B) LC-MRM/MS analysis of nine unlabeled tryptic peptides showing order of elution. 

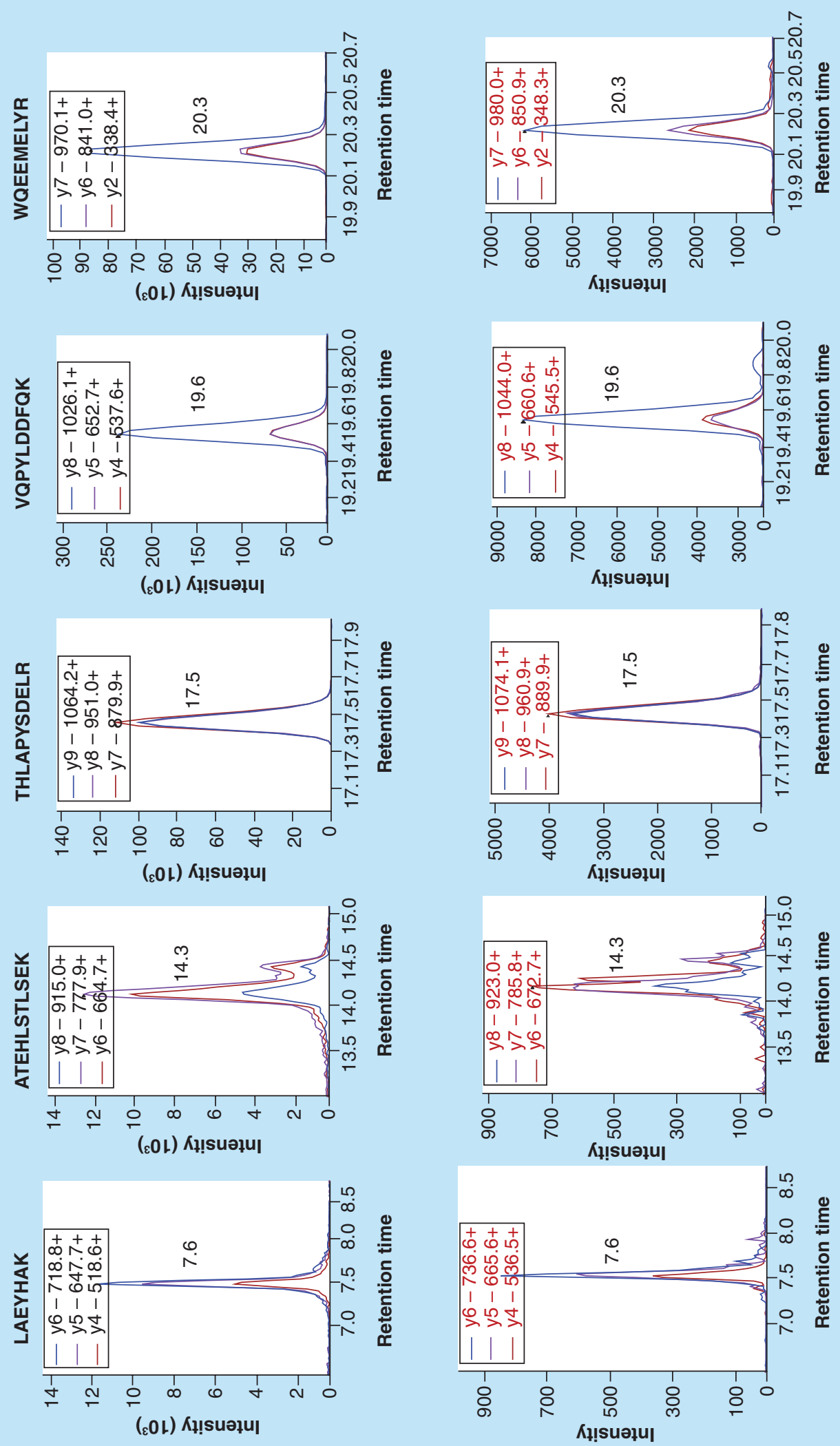

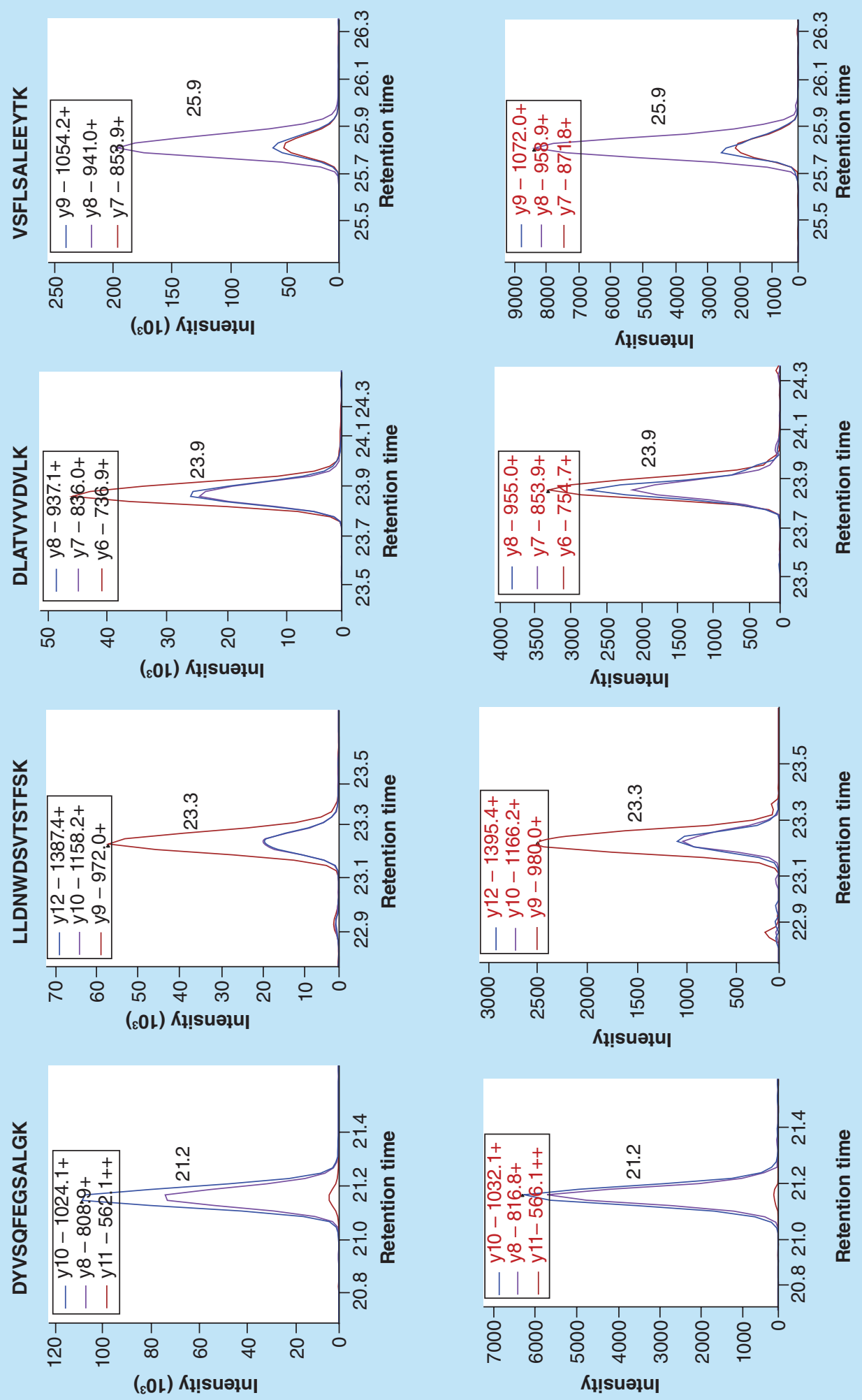
initially 15 potentially useful tryptic peptides were selected for potential use in the quantitative analysis of ApoA-1 according to the ranking in the Peptide Atlas and other reference papers [21-23,53]. These were reduced to a more manageable set of nine peptides, which included all eight of the tyrosine-containing tryptic peptides. They were included because tyrosine has been implicated as potential sites for chlorination and nitration, which is known to alter the biological activity of ApoA-1 [54-58]. The nine tryptic peptides, which spanned amino acids D13 to K238 of the 243 amino acid protein (Figure 1A), eluted in the following order on reversed-phase LC-MS analysis: $\mathrm{L}^{189} \mathrm{AEY}-$ HAK $^{195}, \quad \mathrm{~A}^{196}$ TEHLSTLSEK ${ }^{206}, \quad \mathrm{~T}^{161}$ HLAPYSDELR $^{171}, \mathrm{~V}^{97}$ QPYLDDFQK $^{106}, \mathrm{~W}^{108}$ QEEMELYR $^{116}$, $\mathrm{D}^{28} \mathrm{YVSQFEGSALGK}^{40}, \mathrm{~L}^{46}$ LDNWDSVTSTFSK $^{58}$, $\mathrm{D}^{13}$ LATVYVDVLK $^{23}$ and $\mathrm{V}^{227}$ SFLSALEEYTK $^{238}$ (Figure 1B).

LC-MRM/MS transitions were selected based on the LC-MS/MS spectra obtained on a TSQ Vantage. Initial experiments were conducted with five of the labeled AQUA peptides (Supplementary Figure 2). Unfortunately, the ratios of light to heavy peptides exhibited a wide range, which differed by seven-fold among peptides even though samples were spiked with identical amounts of internal standard. Further, large variations were observed for each peptide determination (3-22\%). Therefore, the accuracy and precision of quantification of ApoA-1 were highly dependent on which particular peptides were chosen. A similar problem was addressed by the Hoofnagle group $[8,26]$. They showed that the coefficients of variation $(\mathrm{CVs})$ of measurements that included the digestion step were more than two-fold higher than the CVs of measurements performed with predigested samples. Additional causes of this inaccuracy may include differences in the behavior of the peptides versus protein from sample extraction step to protein digestion step [59].

Some reports have described the reproducible quantification of ApoA-1 peptides generated from protein calibrators combined with AQUA peptides $[21,23,53]$. For example, Smit et al. [53] used matrix-based protein

Table 2. Accuracy and precision for determination of ApoA-1 by SILAC-labeled ApoA-1 in serum $(n=5)$.

\begin{tabular}{|c|c|c|c|c|c|c|c|c|c|c|c|c|}
\hline \multirow[t]{2}{*}{ Peptide/protein } & \multicolumn{4}{|c|}{ LQC (22.5 mg/dl) } & \multicolumn{4}{|c|}{ MQC (200.0 mg/dl) } & \multicolumn{4}{|c|}{ HQC (400.0 mg/dl) } \\
\hline & Mean & SD & $\mathbf{P} \%$ & $A \%$ & Mean & SD & $\mathbf{P} \%$ & $A \%$ & Mean & SD & $\mathbf{P} \%$ & $A \%$ \\
\hline \multicolumn{13}{|l|}{ Interday $(n=5)$} \\
\hline LAEYHAK & 18.8 & 2.0 & 10.5 & 83.5 & 168.9 & 13.6 & 8.0 & 84.5 & 351.1 & 36.7 & 10.4 & 87.8 \\
\hline ATEHLSTLSEK & 21.6 & 2.9 & 13.4 & 96.0 & 235.0 & 57.8 & 24.6 & 117.5 & 430.7 & 86.7 & 20.1 & 107.7 \\
\hline THLAPYSDELR & 21.9 & 3.4 & 15.6 & 97.1 & 188.4 & 45.2 & 24.0 & 94.2 & 370.4 & 45.6 & 12.3 & 92.6 \\
\hline VQPYLDDFQK & 23.0 & 5.3 & 23.2 & 102.1 & 193.9 & 37.5 & 19.3 & 97.0 & 364.5 & 40.3 & 11.1 & 91.1 \\
\hline WQEEMELYR & 20.3 & 4.2 & 20.7 & 90.4 & 189.2 & 27.8 & 14.7 & 94.6 & 365.5 & 29.6 & 8.1 & 91.4 \\
\hline DYVSQFEGSALGK & 21.3 & 4.0 & 18.7 & 94.8 & 192.6 & 40.6 & 21.1 & 96.3 & 370.9 & 57.4 & 15.5 & 92.7 \\
\hline LLDNWDSVTSTFSK & 22.0 & 2.8 & 12.5 & 97.9 & 179.6 & 34.6 & 19.2 & 89.8 & 369.0 & 46.2 & 12.5 & 92.3 \\
\hline DLATVYVDVLK & 23.5 & 4.2 & 17.7 & 104.6 & 186.3 & 32.0 & 17.2 & 93.1 & 368.8 & 49.3 & 13.4 & 92.2 \\
\hline VSFLSALEEYTK & 23.5 & 3.5 & 15.1 & 104.2 & 200.7 & 47.0 & 23.4 & 100.4 & 376.6 & 66.9 & 17.8 & 94.1 \\
\hline ApoA-1 & 23.4 & 3.2 & 13.6 & 103.8 & 192.5 & 37.4 & 19.4 & 96.3 & 372.0 & 49.1 & 13.2 & 93.0 \\
\hline \multicolumn{13}{|l|}{ Intraday $(n=5)$} \\
\hline LAEYHAK & 19.5 & 0.2 & 1.0 & 86.5 & 207.9 & 35.1 & 16.9 & 104.0 & 397.7 & 72.6 & 18.3 & 99.4 \\
\hline ATEHLSTLSEK & 20.7 & 2.0 & 9.6 & 92.0 & 168.6 & 15.3 & 9.1 & 84.3 & 449.1 & 13.1 & 2.9 & 112.3 \\
\hline THLAPYSDELR & 21.6 & 0.2 & 0.9 & 96.1 & 221.9 & 20.9 & 9.4 & 111.0 & 418.4 & 30.0 & 7.2 & 104.6 \\
\hline VQPYLDDFQK & 22.0 & 0.2 & 0.7 & 97.8 & 224.3 & 14.0 & 6.2 & 112.2 & 399.5 & 35.2 & 8.8 & 99.9 \\
\hline WQEEMELYR & 22.4 & 0.1 & 0.2 & 99.4 & 208.3 & 12.2 & 5.9 & 104.1 & 367.6 & 28.0 & 7.6 & 91.9 \\
\hline DYVSQFEGSALGK & 21.7 & 0.4 & 1.7 & 96.4 & 229.3 & 18.3 & 8.0 & 114.7 & 417.1 & 47.0 & 11.3 & 104.3 \\
\hline LLDNWDSVTSTFSK & 21.3 & 0.1 & 0.7 & 94.8 & 211.9 & 30.4 & 14.3 & 105.9 & 407.0 & 33.2 & 8.2 & 101.8 \\
\hline DLATVYVDVLK & 23.6 & 1.2 & 5.0 & 104.8 & 214.6 & 19.2 & 8.9 & 107.3 & 413.8 & 37.6 & 9.1 & 103.4 \\
\hline VSFLSALEEYTK & 22.1 & 0.2 & 0.9 & 98.0 & 231.1 & 18.1 & 7.8 & 115.6 & 447.7 & 48.6 & 10.9 & 111.9 \\
\hline АроA-1 & 24.9 & 0.3 & 1.1 & 110.8 & 236.1 & 14.8 & 6.3 & 118.1 & 414.5 & 32.4 & 7.8 & 103.6 \\
\hline
\end{tabular}


calibrators that undergo an identical workflow as the unknown specimens for determination of ApoA-1 in patient serum samples. The intra-assay $\mathrm{CV}$ s were $<7 \%$, and interassay CVs were also good $(<9 \%)$. The quantification results may be useful for showing relative differences and trends between patient and control groups. However, this approach utilized an external calibration, which partially balanced the difference between endogenous protein and protein-generated peptide, but potential digestion inadequacies would not be accounted for by AQUA peptides, which were added after digestion. A recent study reported the use of purified stable isotope labeled (SIL) ApoA-1 as internal standard [60]. No improvement in precision was observed with the use of SIL-ApoA-1 instead of SILpeptide standards; however, the assay accuracy was not fully validated. Furthermore, the SILAC-ApoA-1 contained a His tag and V5-epitope tag so the SIL-protein was not identical with the endogenous form [36].

\section{Confirmation of ApoA-1 standard \\ \& SILAC-labeled ApoA-1}

The unlabeled ApoA-1 standard used for generating calibration curve and QCs was human ApoA-1 isolated from human HDL (ProSpec, East Brunswick, NJ, USA). The ApoA-1 protein concentration was confirmed by absorption at $280 \mathrm{~nm}$ by a Synergy HT UV-Vis reader (BioTek, Winooski, VT, USA, extinction coefficient $=31,720 \mathrm{M}^{-1} \mathrm{~cm}^{-1} ; \mathrm{b}=0.05 \mathrm{~cm}$ ) (Supplementary Table 4) [61,62]. Identity and purity of ApoA-1 standard and SILAC-labeled ApoA-1 were both confirmed by SDS-PAGE gel and LC-MRM/MS assay. SDS-PAGE gel separation followed by Coomassie blue staining revealed a prominent band at $30 \mathrm{kDa}$ with purity greater than $95 \%$. Tryptic digestion of this band followed by LC-MRM/MS analysis confirmed that SILAC-ApoA-1 was isotopically labeled with $\left[{ }^{13} \mathrm{C}_{6}^{15} \mathrm{~N}_{2}\right]$-lysine and $\left[{ }^{13} \mathrm{C}_{9}{ }^{15} \mathrm{~N}_{1}\right]$-tyrosine with labeling efficiency (heavy / (light + heavy)*100\%) $>95 \%$ for all monitored peptides (Supplementary Table 5). Standard curves for serum ApoA-1 peptides were determined after extraction, PAGE purification and trypsin hydrolysis of the endogenous protein and its SILAC internal standard. Area ratios of the resulting nine tryptic peptides were calculated by skyline which were the total area of the three MRM transitions for each peptide compared with the total area of the corresponding three MRM transitions from its stable isotope labeled peptide internal standard (Supplementary Table 3 \& Figure 2). Replicate comparison of peak areas and retention time were monitored by Skyline for all nine peptides (Table 2).

The $\mathrm{r}^{2}$ values for standard curves run on three separate days were $>0.997$ and back-calculated values for the standards had precision and accuracy that met

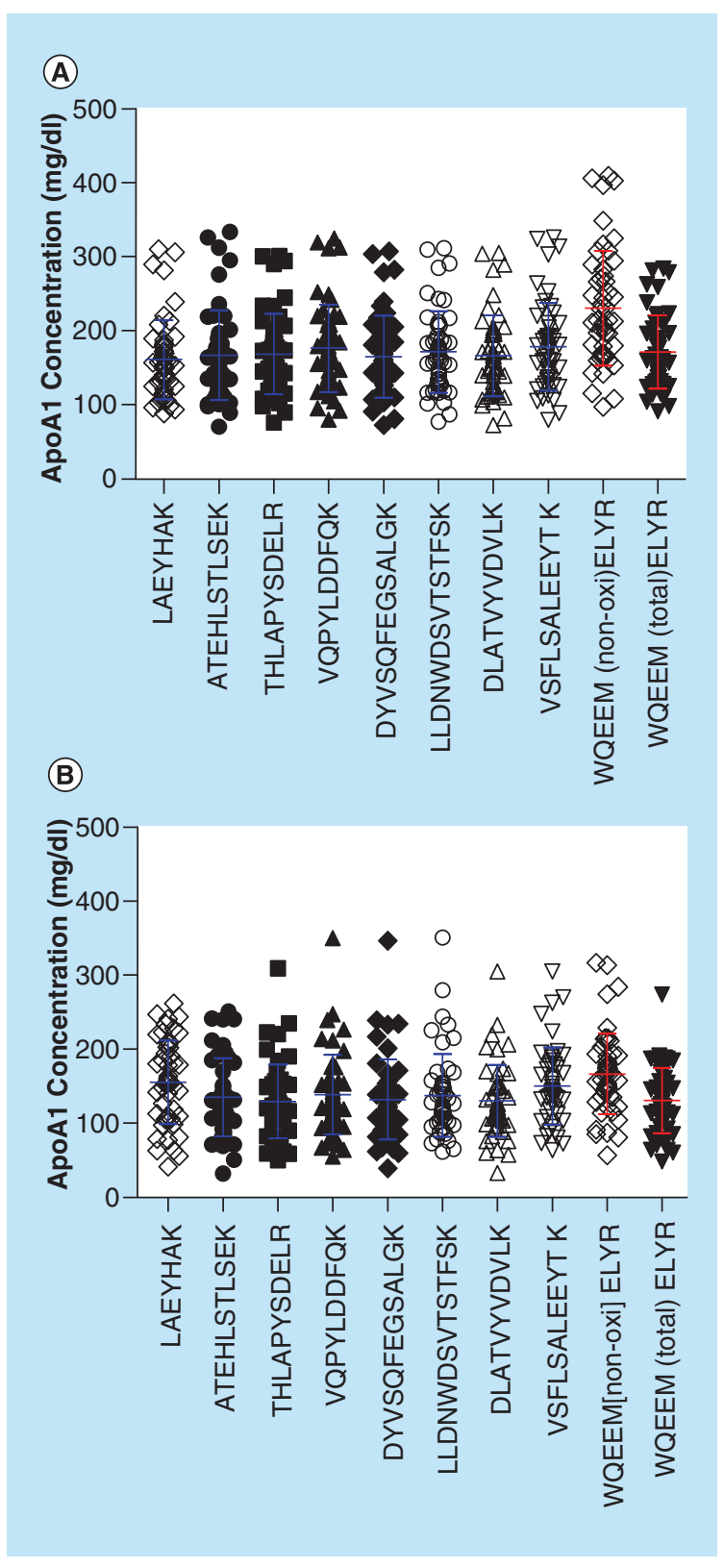

Figure 3. ApoA-1 quantification in 50 nonsmokers (A) and 50 smokers (B) by LC-MRM/MS method with nonoxidized methionine and total-methionine $(n=50$, mean $\pm S D)$.

$M($ nonoxi): Nonoxidized methionine, $M($ total):

nonoxidized methionine + oxidized methionine.

FDA recommendations (Supplementary Table 6) [49]. This confirmed that a linear response from peptides spanning across the entire protein could be obtained using a SILAC protein standard.

Plasma levels of high density lipoprotein (HDL) and ApoA-1 inversely correlate with the risk of developing coronary artery disease [63]. Some evidence implicates ApoA-1 oxidation in modulating further protein oxidation and contributing to atherogenesis in humans. In the present study, peptide WQEEMELYR, con- 
taining methionine, was chosen for monitoring the influence of methionine oxidation on endogenous and SILAC-labeled ApoA-1. Quantification of ApoA-1 based on nonoxidized methionine WQEEM(nonox) ELYR and total methionine WQEEM(total)ELYR are shown in Figure 3. ApoA-1 concentrations in patient samples were higher and variations of nine signature peptides $(\mathrm{CV} \%)$ were higher when calculations were from nonoxidized methionine, but the $\mathrm{CV} \%$ dropped to $15 \%$ for all 100 patient samples when total-methionine was used for quantification (Supplementary Table 7). Peptide variations could be caused by different rates of methionine oxidation between endogenous ApoA-1 and SILAC-labeled ApoA-1. This follows from the

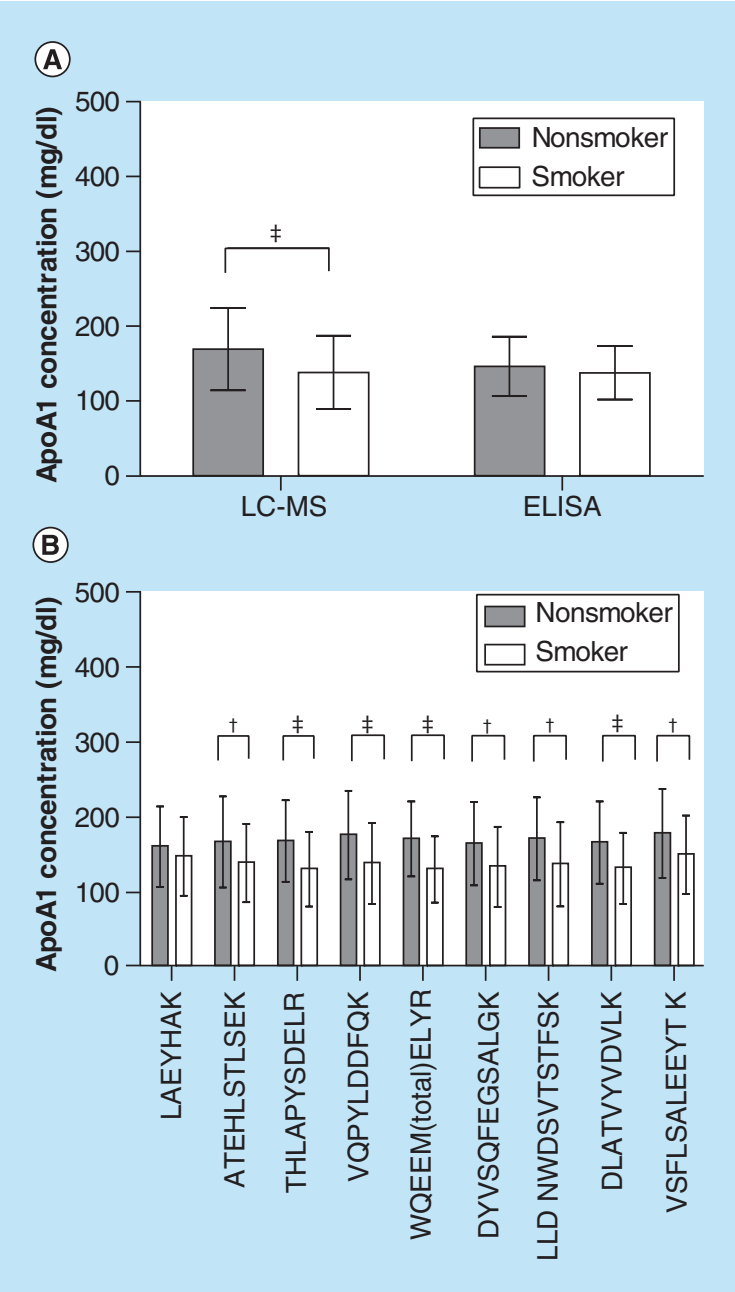

Figure 4. ApoA-1 concentrations in $\mathbf{5 0}$ nonsmokers and 50 smokers. (A) Mean $( \pm S D)$ ApoA-1 concentrations by LC-MRM/MS method with SILAC-labeled ApoA-1 and by ELISA assay. (B) Mean $( \pm S D)$ concentrations of nine signature peptides by LC-MRM/MS.

${ }^{\dagger} \mathrm{p}<0.05$.

${ }^{\ddagger} p<0.01$.

$M$ (total): Nonoxidized methionine + oxidized methionine. fact that many studies prefer to exclude peptides with methionine to avoid discrepancies in results that arise from oxidation. However, our study suggests that if no appropriate methionine-free peptides are available for quantification, the use of peptides containing methionine are feasible by combining signals of unmodified and oxidized peptides coupled with SILAC-labeled protein standard.

Method validation using SILAC-labeled ApoA-1

Mouse ApoA-1 has no identical tryptic peptides overlapping with the nine peptides we used for determination of human ApoA-1 (Figure 1A). Therefore, mouse serum was used as surrogate serum for the preparation of standard curves and QCs. Typical LC-MRM/MS chromatograms of the nine tryptic peptides and their stable isotope labeled (heavy) isotope internal standards are shown in Figure 2. The uniqueness of peptides was checked by using the human proteome downloaded from NIST as the background proteome. The nine signature peptides that were chosen in this study were unique for ApoA-1. All chromatograms used for analysis gave Gaussian peak shapes and were clearly resolved from any closely eluting analytes. Calibration curves for each peptide were constructed from the ratios of peak areas of endogenous peptide to corresponding internal standard peptide generated from SILAC-ApoA-1. Linear standard curves were obtained for each peptide with $r^{2}$ values $>0.995$ from 15.6 to $500.0 \mathrm{mg} / \mathrm{dl}$ (Supplementary Figures 3A-l). The mean area ratios for the nine peptides were then used to construct a standard curve for ApoA-1 (Supplementary Figure 3J). Satisfactory linearity was observed from 15.6 to $500.0 \mathrm{mg} / \mathrm{dl}$ at protein level with linear regression correlation coefficients all better than 0.997 (Supplementary Table 6). The LLOQ was determined as $15.6 \mathrm{mg} / \mathrm{dl}$ with accuracy and precision of less than $25 \%$ and with a residual of less than $10 \%$. Method accuracy and precision were obtained for the analysis of all three QC serum samples (Table 2). For the LQC $(22.5 \mathrm{mg} / \mathrm{dl}), \mathrm{MQC}(200.0 \mathrm{mg} / \mathrm{dl})$ and HQC $(400.0 \mathrm{mg} / \mathrm{dl})$, the intraday accuracies of peptides were $84.3-115.6 \%$; the intraday precisions of peptides were $0.2-18.3 \%$; the interday accuracies of peptides were $83.5-117.4 \%$ and the interday precisions of peptides were $8.0-24.6 \%$. Overall, the intraday accuracy and precision of ApoA-1 protein was 103.6-118.1\% and $1.1-7.8 \%$, respectively. The interday accuracy and precision of ApoA-1 protein was $93.0-103.8 \%$ and $13.2-19.4 \%$, respectively. LQC, MQC and HQC samples that were re-analyzed after $48 \mathrm{~h}$ standing in the autosampler $\left(4^{\circ} \mathrm{C}\right)$ gave essentially identical data to that obtained from the original analyses. A matrix effect could alter the absolute responses of the analyte 


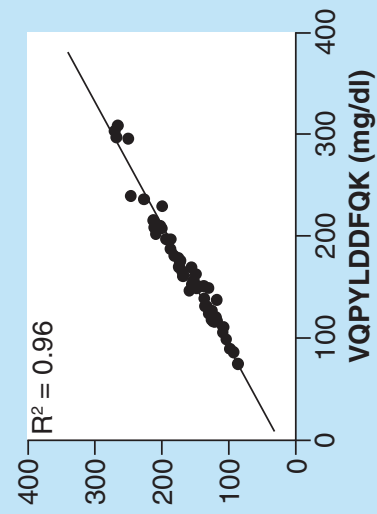

(Ір/6ш) чиㄱ

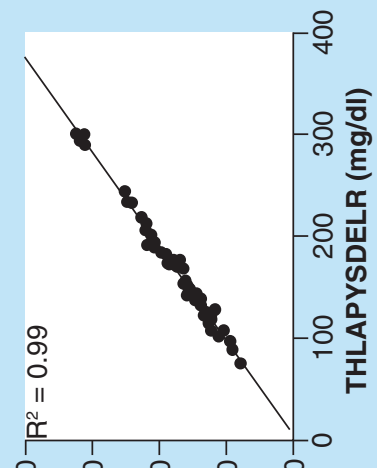

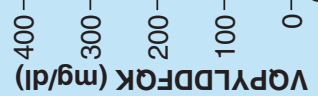

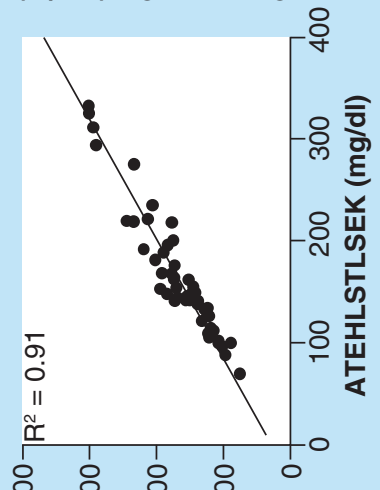

(Ip/6u) ले

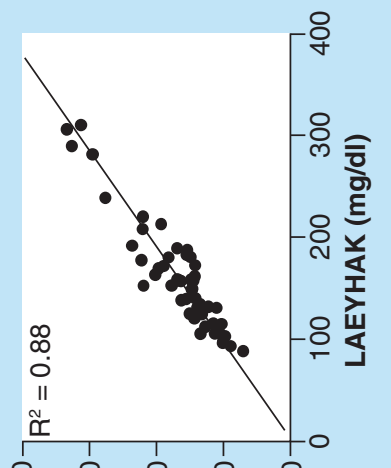

(«)

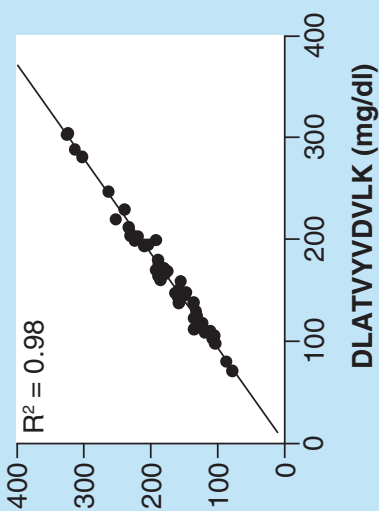

(Ip/бய) 싯ㅋㄱㄴㄱㅗ
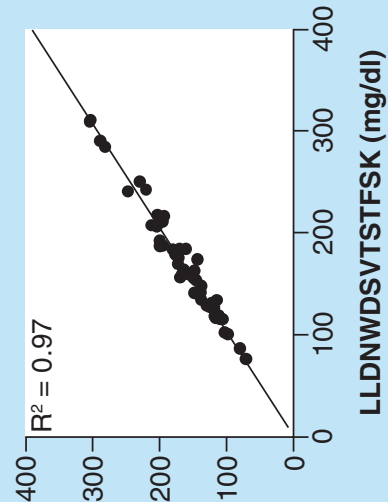

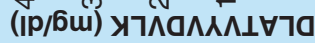

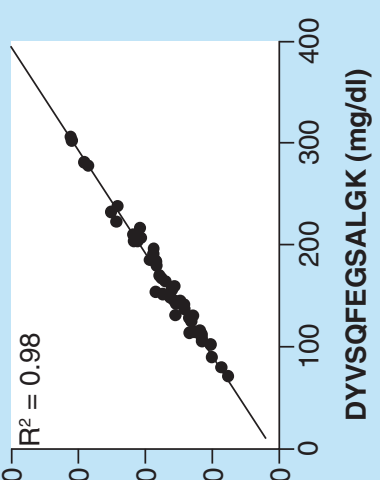

8. 8े 8े 80

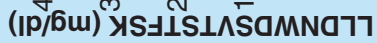

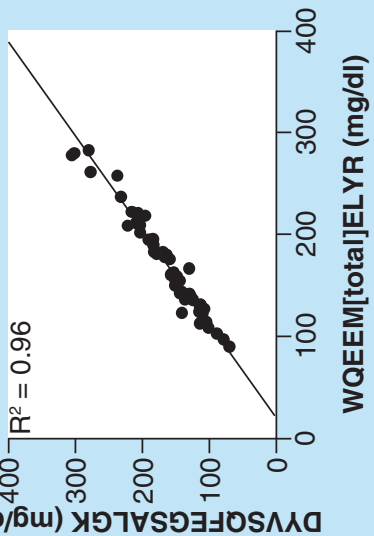

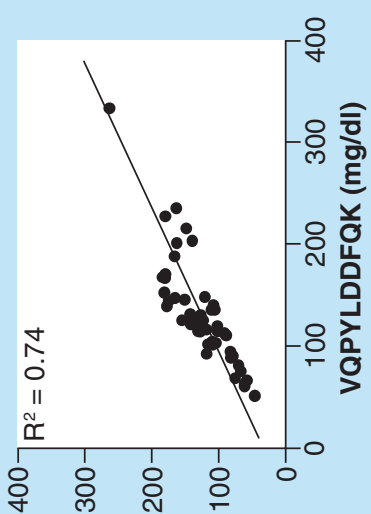

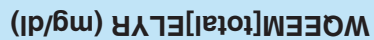

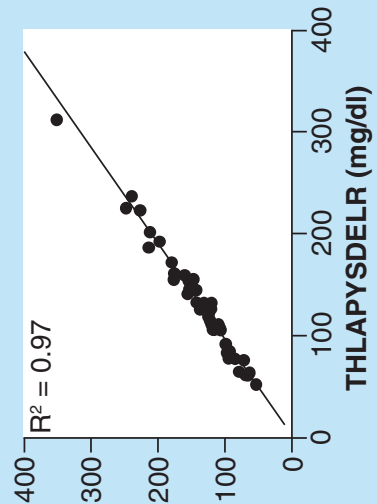

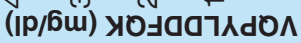

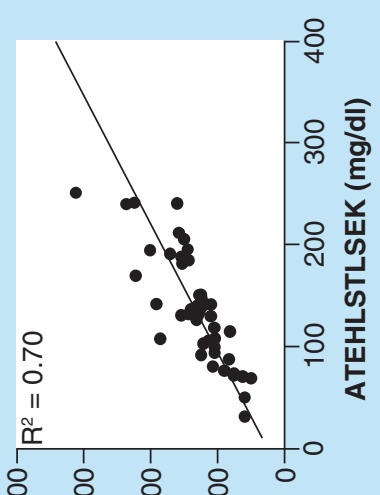

(Ip/6u) yาง

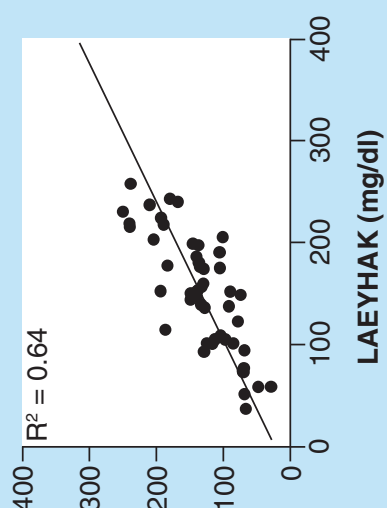

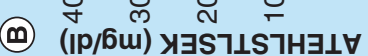

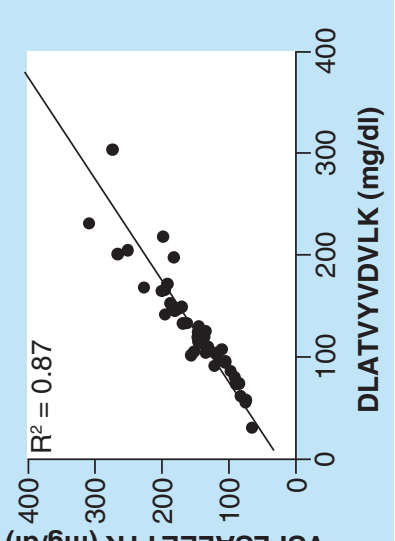

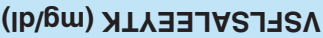

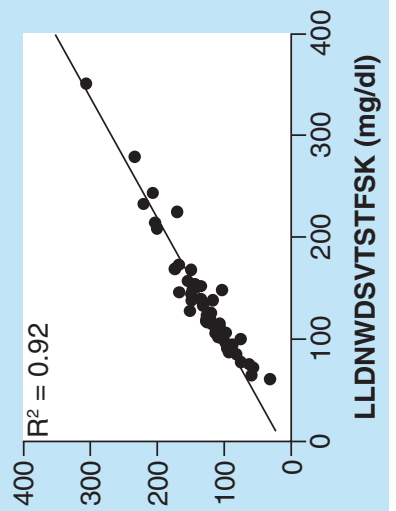

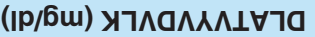

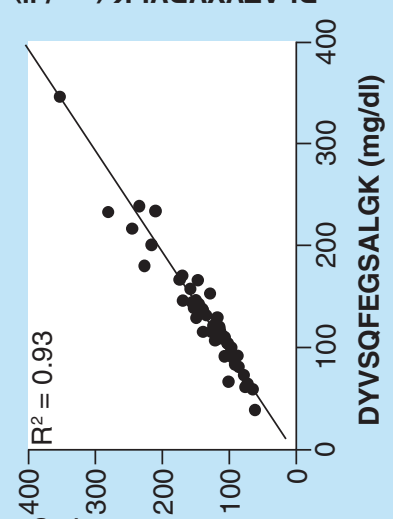

(Ip/6u) Y्रS $\perp S \perp \Lambda S A M N a 77$

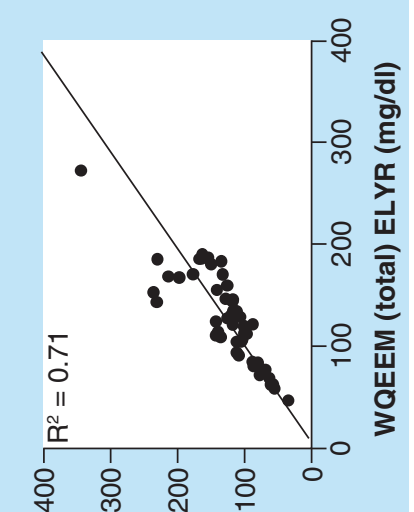

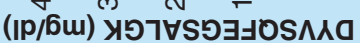


and internal standard but would not change the ratio of the responses because the analyte and internal standard have identical physicochemical properties. To ensure that any possible effect on the absolute response would not affect the LOD, three different amounts of SILAC-labeled ApoA-1 (225, 450 and 900 ng) were spiked into pooled human serum (10 nonsmokers, 10 smokers) and pooled mouse serum. The absolute LC-MRM/MS responses for the nine SILAC ApoA-1 tryptic peptides from the two human serum and the mouse serum samples were within $25 \%$ indicating that there was no significant matrix effect in the range of ApoA-1 concentrations that the assay was validated for.

ApoA-1 level in nonsmokers \& smokers

A total of 100 serum samples (50 nonsmokers and 50 smokers) were processed using the current validated LC-MRM/MS method. All ApoA-1 concentrations were within the linear range of standard curves. The mean concentrations ( \pm SD) of ApoA-1 in nonsmokers and smokers were $169.4 \mathrm{mg} / \mathrm{dl}( \pm 55.1)$ and $138.2 \mathrm{mg} / \mathrm{dl}( \pm 48.9)$, respectively (Figure 4A). The smokers had statistically significant lower serum ApoA-1 concentrations compared with nonsmokers $(\mathrm{p}<0.01)$. All nine serum ApoA-1 tryptic peptides also showed the same trends in both groups, with a statistically significant reduction in eight of the peptides in smokers compared with nonsmokers (Figure 4B).

The concentrations of pairs of ApoA- 1 tryptic peptides that eluted consecutively from the LC column were compared with each other (Figure 5). These eight pairs of peptides were representative of 72 possible combinations of all peptide pairs. Excellent correlations were found for all nine of the serum ApoA-1 tryptic peptides from nonsmokers with $r^{2}$ values that ranged from 0.88 to 0.99 (Figure 5A). Excellent correlations were also found for six of the serum ApoA-1 tryptic peptides from smokers with $r^{2}$ values that ranged from 0.87 to 0.97 (Figure 5B). However, poorer correlations were found for three of the peptides LAEYHAK $\left(\mathrm{r}^{2}=0.64\right)$, ATEHLSTLSEK $\left(r^{2}=0.70\right)$ and WQEEMELYR $\left(r^{2}=0.71\right)$ suggesting that there could be post-translational modifications on these peptides (Figure 5B). Agger et al. [21] reported that during protease digestion, peptide ATEHLSTLSEK reached a maximum in $2-4 \mathrm{~h}$ and then plateaued or decreased from 5 to $21 \mathrm{~h}$. A similar result was observed by van den Broek et al. [12] when they systematically evaluated trypsin digestion efficiency for the absolute quantification of ApoA-1. However, this would not explain our finding because the rate of hydrolysis would be identical for the labeled and unlabeled tryptic peptides released at the same rate from the labeled and unlabeled proteins, respectively. Furthermore, the correlations found in the nonsmoker samples for LAEYHAK $\left(r^{2}=0.88\right)$, ATEHL-
STLSEK $\left(r^{2}=0.91\right)$ and WQEEMELYR $\left(r^{2}=0.96\right)$ were excellent. In the study of van den Broek et al. [12], the poorest correlation was observed between peptides VQPYLDDFQK and VSKLSALEEYTK $\left(r^{2}=0.77\right)$, which was thought to be due to different digestion kinetics of slowly formed peptide VQPYLDDFQK, compared with the rapidly formed peptide VSKLSALEEYTK. Nevertheless, in another study reported by Smit et al. [53], a good correlation of these two peptides was obtained $\left(r^{2}=0.90\right)$ from 11 patient samples. In our study, VQPYLDDFQK and VSKLSALEEYTK showed good correlation in both nonsmokers $\left(r^{2}=0.98\right)$ and smokers $\left(r^{2}=0.90\right)$ (Supplementary Figure 4). This confirms that the spike in SILAC-labeled ApoA-1 internal standard procedure corrected for variability in peptide forming during the hydrolysis procedure. Tyrosine-192 has been reported as the predominant site of both nitration and chlorination by myeloperoxidase (MPO) in vivo and was also the major site of nitration by peroxynitrite (ONOO-) in vitro [54,56-58]. In our study, the correlation of peptide LAEY192HAK $\left(r^{2}=0.88\right)$ was good in nonsmokers, while poor $\left(r^{2}=0.64\right)$ in smokers. Our data also provides additional confirmation that evaluation of trypsin digestion efficiency before choosing final peptides for quantification as suggested previously by Miller $e$ t al. [11] can further improve the precision and accuracy of protein quantification.

\section{Immunoassay \& LC-MRM/MS}

A commercial ApoA-1 human ELISA Kit (Abcam, ab108804, Cambridge, MA, USA) was used in our study for comparative measurement of ApoA-1 by immunoassay. In contrast to the values obtained by LC-MRM/MS, the mean concentrations $( \pm S D)$ of serum ApoA-1 obtained by immunoassay for nonsmokers of $146.3 \mathrm{mg} / \mathrm{dl}( \pm 39.7)$ and smokers of $137.8 \mathrm{mg} / \mathrm{dl}( \pm 39.7)$ were not significantly different (Figure 4A). Unacceptable correlations were found between the LC-MRM/MS and ELISA serum ApoA-1 methods for both the nonsmokers and the smokers either from a Deming regression plot [50] or by a Bland-Altman comparison [51,52]. The Deming regression showed a p-value of 0.214 for the nonsmokers (Figure 6A) and a p-value of 0.102 for the smokers (Figure 6B). The Bland-Altman Correlations did not meet the predefined acceptance limit criteria of 0.80 for the lower limit of agreement and 1.25 for the upper limit of agreement with data from either the nonsmokers (Figure 6C) or the smokers (Figure 6D).

\section{Conclusion}

Absolute quantification of serum proteins relies heavily on two major bioanalytical approaches that involve the use of either stable isotope labeled pep- 


\section{(A)}

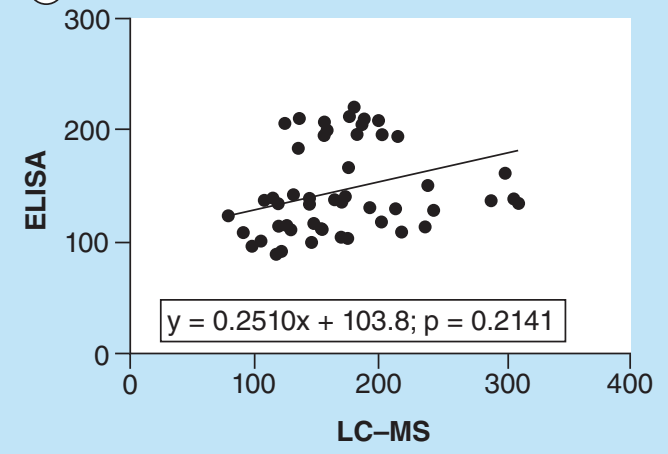

(C)

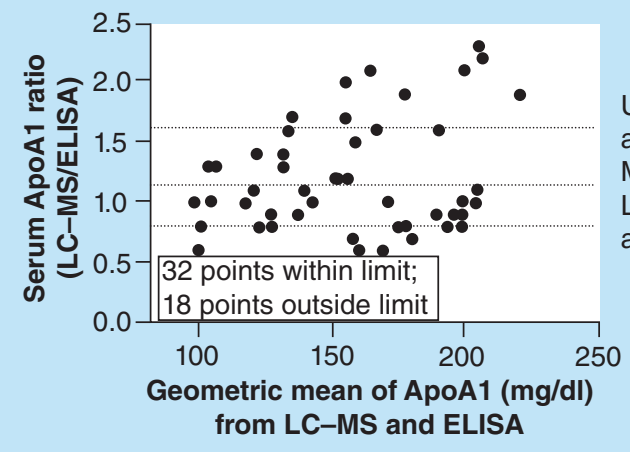

(B)

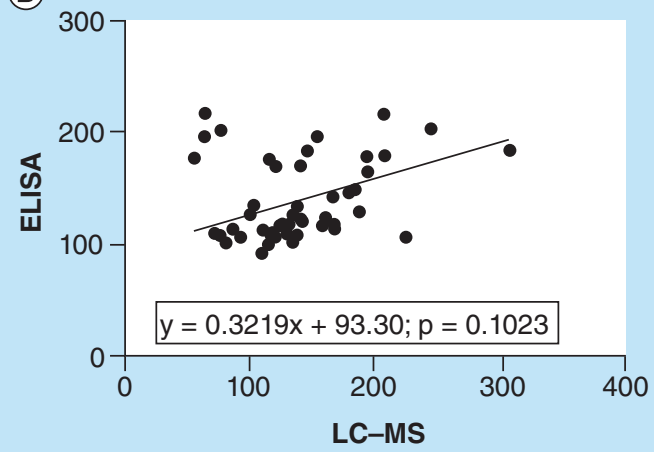

(D)

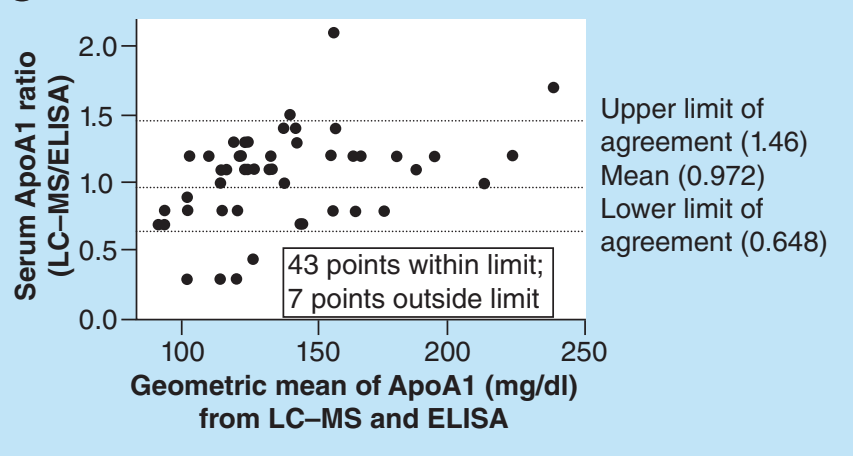

Figure 6. Comparison of serum ApoA-1 concentrations determined by LC-MRM/MS or ELISA. (A) Deming regression for 50 nonsmokers. (B) Deming regression for 50 smokers. (C) Bland-Altman plot for 50 nonsmokers showing a large discrepancy between the two methods. (D) Bland-Altman plot for 50 smokers showing a large discrepancy between the two methods. The Bland-Altman plots are presented as the ratio of a serum ApoA-1 concentration determined by LC-MS compared with that determined by ELISA against the geometric mean of the concentration. The predefined acceptance limit criteria were 0.80 for the lower limit of agreement and 1.25 for the upper limit of agreement.

tide (AQUA) internal standards [17] coupled with LC-MRM/MS [11,12,64] or immunoassay-based procedures such as ELISA [65]. Unfortunately, both of these methods have potential problems that cannot be fully evaluated without an alternative gold standard method for confirmation. In the case of AQUAlabeled peptide internal standards, they cannot be used to track protein recovery or efficiency of protein digestion prior to LC-MS analysis. Therefore, it is possible to obtain very high precision and accuracy for the relevant peptides as well as excellent precision for protein quantification. However, accuracy of protein quantification cannot be unequivocally determined because there could be selective losses during protein extraction and/or the labeled peptides could undergo differential decomposition during the protease hydrolysis procedure [48]. In the case of immunoassays, absolute quantification can be confounded by cross-reaction with other serum proteins in the matrix or constituents in the matrix that affect the antibody-antigen interaction [8]. The use of SILAC methodology has allowed for relative quantification to be conducted successfully. However, it is rare to find that rigorous bioanalytical validations of SILAC-based methods are conducted using pure protein standards.

We have developed an approach that employs the transfection of human cells with an appropriate plasmid so that large amounts of stable isotope labeled protein can be produced. This is a better approach than the alternative use of insect cells where the labeled protein generated could be misfolded and so might not track with the endogenous protein during protease digestion [36]. Using a spike-in SILAC internal standard coupled with analysis by LC-MRM/MS, we have found an excellent correlation in precision and accuracy for all nine peptides that span the 243 amino acids of ApoA-1 protein. After rigorous validation of the assay (Table 2 ), an $18.4 \%$ reduction in serum ApoA-1 concentrations was found in tobacco smokers $(138.2 \mathrm{mg} / \mathrm{dl})$ when compared with nonsmokers (169.4 mg/dl) (Figure 4A).

A commercial ELISA kit showed a very poor correlation with the spike-in SILAC protein LC-MRM/MS 
assay for serum ApoA-1 from the nonsmokers (Figure 6A) and smokers (Figures 6B). Furthermore, the ELISA kit was unable to distinguish nonsmoker and smoker serum ApoA-1 levels (Figure 4A). Interestingly, there was a relatively poor correlation in the LC-MRM/MS assay for three of the tryptic peptides (LAEYHAK, ATEHLSTLSEK and WQEEMELYR) when compared with the six other tryptic peptides in the serum ApoA-1 that was obtained from smokers (Figure 5B). In contrast, there was an excellent correlation of these three peptides with other peptides in the ApoA-1 obtained from nonsmokers (Figure 5A). This suggests that there could be post-translational modifications on these three peptides. It has been shown that Y-192 on peptide LAEYHAK can be chlorinated and nitrated [54-58,66]. However, there are no reported post-translational modifications on the other two peptides. Current studies are being conducted in order to identify potential modifications on the ApoA-1 from smokers as additional biomarkers.

\section{Future perspective}

Quantification using SILAC labeled proteins has been used in numerous proteomics studies. However, rigorous method validation using a full-length stable isotope labeled protein internal standard has been used rarely. In the present study, full validation was performed by the use of LC-MRM/MS and nine tryptic peptides generated from native ApoA-1 and SILAC-labeled ApoA-1 prepared in human kidney HEK cell line. This methodology can be employed to explore subtle changes in ApoA-1 levels as a potential biomarker of cardiovascular disease and as a biological response indicator for tobacco smoking to complement the use of urinary nicotine metabolites [67], NNAL [68], isoprostanes [69] and 8-oxo-dGuo [70]. It will also serve as a gold standard to validate other LC-MS and immunoassay-based procedures for serum ApoA-1. It is noteworthy that the stable isotope peptide (AQUA) internal standards did not provide adequate accuracy and specificity for the analysis of serum ApoA-1 (Supplementary Figure 2). It will also be possible to apply this methodology to other serum apolipoproteins for a better understanding of their biological activity and potential post-transitional modifications in vivo. This is important when commercially available ELISA kits might fail to detect the differences in these potential biomarkers.

The stable isotope dilution LC-MS assay for serum ApoA-1 that we have developed is complex and can only be performed in a limited number of laboratories. However, unlike widely used simpler and less specific assays such as ELISAs, it can provide an accurate and highly reproducible assessment of serum ApoA-1 concentrations. Reduced levels of serum ApoA-1 are associated with an increased risk for coronary heart disease (such as for smokers) and so this assay will have significant clinical utility in identifying individuals at risk. The assay will also have clinical utility for providing definitive information on the effects of smoking cessation as well as therapeutic interventions in other high risk populations with HMG-CoA-reductase inhibitors such as rosuvastatin and atorvastatin [71] and fibrates such as fenofibrate [72] or dietary interventions with saturated and cis-monounsaturated fatty acids [73]. Such individualization of therapy is currently not possible with the assay methodology that is available for analyzing serum ApoA-1 concentrations in most clinical laboratories.

\section{Author contributions}

All of the authors participated in the design of the study and in analysis of the results. Q Wang, S Zhang, CM Busch, $C$ Mesaros, K Rangiah and NW Snyder performed the extractions and conducted the LC-MRM/MS experiments. $\mathrm{L}$ Guo prepared and analyzed the labeled ApoA-1. Q Wang, W Jian, N Weng and IA Blair wrote the manuscript with significant input from all of the authors. All of the authors read and approved the final manuscript.

\section{Supplementary data}

To view the supplementary data that accompany this paper please visit the journal website at www.future-science/doi/ full/10.4155/bio.15.195

\section{Financial \& competing interests disclosure}

This work was supported by NIH grants P30ES013508 and T32ES019851. The authors have no other relevant affiliations or financial involvement with any organization or entity with a financial interest in or financial conflict with the subject matter or materials discussed in the manuscript apart from those disclosed.

No writing assistance was utilized in the production of this manuscript.

\section{Ethical conduct of research}

The authors state that they have obtained appropriate institutional review board approval or have followed the principles outlined in the Declaration of Helsinki for all human or animal experimental investigations. In addition, for investigations involving human subjects, informed consent has been obtained from the participants involved.

\section{Open Access}

This work is licensed under the Attribution-NonCommercialNoDerivatives 4.0 Unported License. To view a copy of this license, visit http://creativecommons.org/licenses/by-nc-nd/4.0/ 


\section{Executive summary}

\section{Materials \& methods}

- Recombinant apolipoprotein A1 (ApoA-1) labeled with $\left[{ }^{13} \mathrm{C}_{6}^{15} \mathrm{~N}_{2}\right]$-lysine and $\left[{ }^{13} \mathrm{C}_{9}^{15} \mathrm{~N}_{1}\right]$-tyrosine expressed in the human kidney HEK293 cell line, was used as a SILAC internal standard for the absolute quantification of ApoA-1 in human serum samples.

- Quantification of ApoA-1 was performed by stable isotope dilution LC-MRM/MS analysis using seven tyrosine-containing peptides and two additional peptides.

- The influence of methionine oxidation on ApoA-1 quantification was evaluated by monitoring oxidized and nonoxidized methionine.

\section{Results \& discussion}

- The LC-MRM/MS method was fully validated using nine tryptic peptides generated from native ApoA-1 and SILAC-labeled ApoA-1.

- All nine tryptic peptides showed the same trends in the 50 nonsmokers and 50 smokers.

- Serum ApoA-1 levels were $18.4 \%$ lower in smokers $(n=50)$ compared with nonsmokers $(n=50)$.

- Peptide correlation results suggested that there were unidentified post-translational modifications present on tryptic peptides LAEYHAK, ATEHLSTLSEK and WQEEMELYR from smoker's serum ApoA-1.

- Poor correlations were found between LC-MRM/MS and an ELISA-based method.

Future perspective

- Subtle changes in serum ApoA-1 levels as well as effects of tobacco smoking on serum ApoA-1 can be monitored with this new LC-MRM/MS method.

- The new method will serve as a gold standard to validate other LC-MS and immunoassay-based procedures for serum ApoA-1.

\section{References}

Papers of special note have been highlighted as:

- of interest; $\bullet \bullet$ of considerable interest

1 De Bock M, Beguin Y, Leprince P et al. Comprehensive plasma profiling for the characterization of graft-versus-host disease biomarkers. Talanta 125, 265-275 (2014).

2 Rader DJ, Hovingh GK. HDL and cardiovascular disease. Lancet 384(9943), 618-625 (2014).

3 Haarbo J, Hassager C, Schlemmer A, Christiansen C. Influence of smoking, body fat distribution, and alcohol consumption on serum lipids, lipoproteins, and apolipoproteins in early postmenopausal women. Atherosclerosis 84(2-3), 239-244 (1990).

4 Slagter SN, van Vliet-Ostaptchouk JV, Vonk JM et al. Associations between smoking, components of metabolic syndrome and lipoprotein particle size. BMC Med. 11, 195 (2013).

5 Miller RA, Spellman DS. Mass spectrometry-based biomarkers in drug development. Adv. Exp. Med. Biol. 806, 341-359 (2014).

6 Miller RA, Winrow CJ, Spellman DS et al. Quantitative proteomics in laser capture microdissected sleep nuclei from rat brain. J. Neurogenet. 28(1-2), 136-145 (2014).

7 Köhler K, Seitz H. Validation processes of protein biomarkers in serum - a cross platform comparison. Sensors 12, 12710-12728 (2012).

8 Hoofnagle AN, Wener MH. The fundamental flaws of immunoassays and potential solutions using tandem mass spectrometry. J. Immunol. Methods 347(1-2), 3-11 (2009).

9 Wild D. Standardization and calibration. In: The Immunoassay Handbook Wild D (Ed.). Elsevier, Oxford, UK, 167-176 (2005).
10 Oe T, Ackermann BL, Inoue $\mathrm{K}$ et al. Quantitative analysis of amyloid beta peptides in cerebrospinal fluid of Alzheimer's disease patients by immunoaffinity purification and stable isotope dilution liquid chromatography/negative electrospray ionization tandem mass spectrometry. Rapid Commun. Mass Spectrom. 20(24), 3723-3735 (2006).

11 Pritchard C, Quaglia M, Ashcroft AE, O’Connor G. Considering the advantages and pitfalls of the use of isotopically labeled protein standards for accurate protein quantification. Bioanalysis 3(24), 2797-2802 (2011).

-• Review of the challenges and benefits of using isotopically labeled protein standards for accurate protein quantification.

12 van den Broek I, Smit NP, Romijn FP et al. Evaluation of interspecimen trypsin digestion efficiency prior to multiple reaction monitoring-based absolute protein quantification with native protein calibrators. J. Proteome Res. 12(12), 5760-5774 (2013).

13 Shi T, Su D, Liu T et al. Advancing the sensitivity of selected reaction monitoring-based targeted quantitative proteomics. Proteomics 12(8), 1074-1092 (2012).

14 Huttenhain R, Malmstrom J, Picotti P, Aebersold R. Perspectives of targeted mass spectrometry for protein biomarker verification. Curr. Opin. Chem. Biol. 13(5-6), 518-525 (2009).

15 Chiu CL, Randall S, Molloy MP. Recent progress in selected reaction monitoring MS-driven plasma protein biomarker analysis. Bioanalysis 1(4), 847-855 (2009).

16 Rauh M. LC-MS/MS for protein and peptide quantification in clinical chemistry. J. Chromatogr. B 883-884), 59-67 (2012).

17 Gerber SA, Rush J, Stemman O, Kirschner MW, Gygi SP. Absolute quantification of proteins and phosphoproteins 
from cell lysates by tandem MS. Proc. Natl Acad. Sci. USA 100(12), 6940-6945 (2003).

18 Gerber SA, Kettenbach AN, Rush J, Gygi SP. The absolute quantification strategy: application to phosphorylation profiling of human separase serine 1126. Methods Mol. Biol. 359), 71-86 (2007).

19 Barr JR, Maggio VL, Patterson DG, Jr. Isotope dilution - mass spectrometric quantification of specific proteins: model application with apolipoprotein A-I. Clin. Chem. 42(10), 1676-1682 (1996).

20 von Zychlinski A, Williams M, McCormick S, Kleffmann T. Absolute quantification of apolipoproteins and associated proteins on human plasma lipoproteins. J. Proteomics 106), 181-190 (2014).

21 Agger SA, Marney LC, Hoofnagle AN. Simultaneous quantification of apolipoprotein A-I and apolipoprotein B by liquid-chromatography-multiple- reaction-monitoring mass spectrometry. Clin. Chem. 56(12), 1804-1813 (2010).

- Compares immuoassay and stable isotope dilution LC-MS methods for quantification of apolipoproteins.

22 Ceglarek U, Dittrich J, Becker S, Baumann F, Kortz L, Thiery J. Quantification of seven apolipoproteins in human plasma by proteotypic peptides using fast LC-MS/MS. Proteomics Clin. Appl. 7(11-12), 794-801 (2013).

23 Kay RG, Gregory B, Grace PB, Pleasance S. The application of ultra-performance liquid chromatography/tandem mass spectrometry to the detection and quantitation of apolipoproteins in human serum. Rapid Commun. Mass Spectrom. 21(16), 2585-2593 (2007).

24 Lassman ME, McLaughlin TM, Somers EP et al. A rapid method for cross-species quantitation of apolipoproteins A-I, B 48 and B100 in plasma by ultra-performance liquid chromatography/tandem mass spectrometry. Rapid Commun. Mass Spectrom. 26(2), 101-108 (2012).

25 Lassman ME, McLaughlin TM, Zhou H et al. Simultaneous quantitation and size characterization of apolipoprotein(a) by ultra-performance liquid chromatography/mass spectrometry. Rapid Commun. Mass Spectrom. 28(10), 1101-1106 (2014).

26 Hoofnagle AN, Becker JO, Oda MN, Cavigiolio G, Mayer P, Vaisar T. Multiple-reaction monitoring-mass spectrometric assays can accurately measure the relative protein abundance in complex mixtures. Clin. Chem. 58(4), 777-781 (2012).

-• Example of quantification of apolipoproteins using both stable isotope-labeled peptides and stable isotope-labeled protein by LC-MRM/MS method.

27 Yassine HN, Jackson AM, Reaven PD et al. The application of multiple reaction monitoring to assess Apo A-I methionine oxidations in diabetes and cardiovascular disease. Transl. Proteom. 4-5, 18-24 (2014).

28 Mustafa MG, Petersen JR, Ju H et al. Biomarker discovery for early detection of hepatocellular carcinoma in hepatitis C-infected patients. Mol. Cell Proteomics 12(12), 3640-3652 (2013).

29 Brun V, Dupuis A, Adrait A et al. Isotope-labeled protein standards: toward absolute quantitative proteomics. Mol. Cell Proteomics 6(12), 2139-2149 (2007).
30 Keshishian H, Addona T, Burgess M, Kuhn E, Carr SA. Quantitative, multiplexed assays for low abundance proteins in plasma by targeted mass spectrometry and stable isotope dilution. Mol. Cell Proteomics 6(12), 2212-2229 (2007).

31 Keshishian H, Addona T, Burgess M et al. Quantification of cardiovascular biomarkers in patient plasma by targeted mass spectrometry and stable isotope dilution. Mol. Cell Proteomics 8(10), 2339-2349 (2009).

32 Yan Y, Weaver VM, Blair IA. Analysis of protein expression during oxidative stress in breast epithelial cells using a stable isotope labeled proteome internal standard. J. Proteome. Res. 4(6), 2007-2014 (2005).

33 Hanke S, Besir H, Oesterhelt D, Mann M. Absolute SILAC for accurate quantitation of proteins in complex mixtures down to the attomole level. J. Proteome Res. 7(3), 1118-1130 (2008).

34 Harel M, Oren-Giladi P, Kaidar-Person O, Shaked Y, Geiger T. PROMIS-Quan: a novel proteomic method for plasma biomarker quantification. Mol. Cell Proteomics 14(4), 1127-1136 (2015).

35 Rangiah K, Tippornwong M, Sangar V et al. Differential secreted proteome approach in murine model for candidate biomarker discovery in colon cancer. J. Proteome. Res. 8(11), 5153-5164 (2009).

36 Ciccimaro E, Hanks SK, Yu KH, Blair IA. Absolute quantification of phosphorylation on the kinase activation loop of cellular focal adhesion kinase by stable isotope dilution liquid chromatography/mass spectrometry. Anal. Chem. 81(9), 3304-3313 (2009).

37 Shah SJ, Yu KH, Sangar V, Parry SI, Blair IA. Identification and quantification of preterm birth biomarkers in human cervicovaginal fluid by liquid chromatography/tandem mass spectrometry. J. Proteome Res. 8(5), 2407-2417 (2009).

38 Wehr AY, Hwang WT, Blair IA, Yu KH. Relative quantification of serum proteins from pancreatic ductal adenocarcinoma patients by stable isotope dilution liquid chromatography-mass spectrometry. J. Proteome Res. 11(3), 1749-1758 (2012).

39 Mangrum JB, Martin EJ, Brophy DF, Hawkridge AM. Intact stable isotope labeled plasma proteins from the SILAC-labeled HepG2 secretome. Proteomics 15(18), 3104-3115 (2014).

40 Geiger T, Wisniewski JR, Cox J et al. Use of stable isotope labeling by amino acids in cell culture as a spike-in standard in quantitative proteomics. Nat. Protoc. 6(2), 147-157 (2011).

41 Ishihama Y, Sato T, Tabata T et al. Quantitative mouse brain proteomics using culture-derived isotope tags as internal standards. Nat. Biotechnol. 23(5), 617-621 (2005).

42 Sato T, Ishihama Y, Oda Y. Quantitative proteomics of mouse brain and specific protein-interaction studies using stable isotope labeling. Methods Mol. Biol. 359), 53-70 (2007).

43 Janecki DJ, Bemis KG, Tegeler TJ et al. A multiple reaction monitoring method for absolute quantification of the human liver alcohol dehydrogenase ADH1C1 isoenzyme. Anal. Biochem. 369(1), 18-26 (2007).

44 Geiger T, Cox J, Ostasiewicz P, Wisniewski JR, Mann M. Super-SILAC mix for quantitative proteomics of human tumor tissue. Nat. Methods 7(5), 383-385 (2010). 

Ong SE, Mann M. A practicl
labeling by amino acids in cell culture (SILAC). Nat. Protoc. 1(6), 2650-2660 (2006).

48 Ciccimaro E, Blair IA. Stable-isotope dilution LC-MS for quantitative biomarker analysis. Bioanalysis 2(2), 311-341 (2010).

- A comprensive review describing the use of stable-isotope dilution LC-MS methodology for quantification of biomarkers.

49 A comprensive review describing the use of stable-isotope dilution LC-MS methology for quantification of biomarkers. www.fda.gov/downloads/drugs/guidancecomplianceregul atoryinformation/guidances/ucm368107.pdf

Martin RF. General deming regression for estimating systematic bias and its confidence interval in methodcomparison studies. Clin. Chem. 46(1), 100-104 (2000).

51 Bland JM, Altman DG. Statistical methods for assessing agreement between two methods of clinical measurement. Lancet 1(8476), 307-310 (1986).

52 Bland JM, Altman DG. Agreed statistics: measurement method comparison. Anesthesiology 116(1), 182-185 (2012).

53 Smit NP, Romijn FP, van dB I et al. Metrological traceability in mass spectrometry-based targeted protein quantitation: a proof-of-principle study for serum apolipoproteins A-1 and B100. J. Proteomics 109, 143-161 (2014).

- An application of LC-MRM/MS method for measuremnt of apolipoproteins in serum aiming for implementation of a multiplexed assay with full metrological traceability.

Nicholls SJ, Zheng L, Hazen SL. Formation of dysfunctional high-density lipoprotein by myeloperoxidase. Trends Cardiovasc. Med. 15(6), 212-219 (2005).

55 Zheng L, Settle M, Brubaker G et al. Localization of nitration and chlorination sites on apolipoprotein A-1 catalyzed by myeloperoxidase in human atheroma and associated oxidative impairment in ABCA1-dependent cholesterol efflux from macrophages. J. Biol. Chem. 280(1), 38-47 (2005).

56 Shao B, Pennathur S, Heinecke JW. Myeloperoxidase targets apolipoprotein A-I, the major high density lipoprotein protein, for site-specific oxidation in human atherosclerotic lesions. J. Biol. Chem. 287(9), 6375-6386 (2012).

57 Vivekanandan-Giri A, Slocum JL, Byun J et al. High density lipoprotein is targeted for oxidation by myeloperoxidase in rheumatoid arthritis. Ann. Rheum. Dis. 72(10), 1725-1731 (2013).

58 Huang Y, DiDonato JA, Levison BS et al. An abundant dysfunctional apolipoprotein A-I in human atheroma. Nat. Med. 20(2), 193-203 (2014).

59 Proc JL, Kuzyk MA, Hardie DB et al. A quantitative study of the effects of chaotropic agents, surfactants, and solvents on the digestion efficiency of human plasma proteins by trypsin. J. Proteome Res. 9(10), 5422-5437 (2010).
60 van den Broek I, Romijn FP, Smit NP et al. Quantifying protein measurands by peptide measurements: where do errors arise? J. Proteome Res. 14(2), 928-942 (2015).

61 Pownall HJ, Massey JB, Kusserow SK, Gotto AM Jr. Kinetics of lipid - protein interactions: interaction of apolipoprotein A-I from human plasma high density lipoproteins with phosphatidylcholines. Biochemistry 17(7), 1183-1188 (1978).

62 Pownall HJ, Massey JB, Kusserow SK, Gotto AM Jr. Kinetics of lipid - protein interactions: effect of cholesterol on the association of human plasma high-density apolipoprotein A-I with L-alpha-dimyristoylphosphatidylcholine. Biochemistry 18(4), 574-579 (1979).

63 Stampfer MJ, Sacks FM, Salvini S, Willett WC, Hennekens $\mathrm{CH}$. A prospective study of cholesterol, apolipoproteins, and the risk of myocardial infarction. N. Engl. J. Med. 325(6), 373-381 (1991).

64 Kuzyk MA, Smith D, Yang J et al. Multiple reaction monitoring-based, multiplexed, absolute quantitation of 45 proteins in human plasma. Mol. Cell Proteomics 8(8), 1860-1877 (2009).

65 Zangar RC, Daly DS, White AM. ELISA microarray technology as a high-throughput system for cancer biomarker validation. Expert Rev. Proteomics 3(1), 37-44 (2006).

66 Shao B, Bergt C, Fu X et al. Tyrosine 192 in apolipoprotein A-I is the major site of nitration and chlorination by myeloperoxidase, but only chlorination markedly impairs ABCA1-dependent cholesterol transport. J. Biol. Chem. 280(7), 5983-5993 (2005).

67 Rangiah K, Hwang WT, Mesaros C, Vachani A, Blair IA. Nicotine exposure and metabolizer phenotypes from analysis of urinary nicotine and its 15 metabolites by LC-MS. Bioanalysis 3(7), 745-761 (2011).

68 Bhat SH, Gelhaus SL, Mesaros C, Vachani A, Blair IA. A new liquid chromatography/mass spectrometry method for 4-(methylnitrosamino)-1-(3-pyridyl)-1-butanol (NNAL) in urine. Rapid Commun. Mass Spectrom. 25(1), 115-121 (2011).

69 Mesaros $\mathrm{C}$, Lee $\mathrm{SH}$, Blair IA. Targeted quantitative analysis of eicosanoid lipids in biological samples using liquid chromatography-tandem mass spectrometry. J. Chromatogr. B Analyt. Technol. Biomed. Life Sci. 877(26), 2736-2745 (2009).

70 Mesaros C, Arora JS, Wholer A, Vachani A, Blair IA. 8-oxo-2'-deoxyguanosine as a biomarker of tobacco-smokinginduced oxidative stress. Free Radic. Biol. Med. 53(3), 610-617 (2012).

71 Takagi H, Umemoto T. A meta-analysis of randomized head-to-head trials for effects of rosuvastatin versus atorvastatin on apolipoprotein profiles. Am. J. Cardiol. 113(2), 292-301 (2014).

72 Niesor EJ, Gauthamadasa K, Silva RA et al. Xanthophylls, phytosterols and pre-beta1-HDL are differentially affected by fenofibrate and niacin HDL-raising in a cross-over study. Lipids 48(12), 1185-1196 (2013).

73 Dullens SP, Plat J, Mensink RP. Increasing ApoA-1 production as a target for CHD risk reduction. Nutr. Metab Cardiovasc. Dis. 17(8), 616-628 (2007). 